\title{
A preliminary assessment of sexual transmitted infections (STIs) in Sri Lanka: District-wise overview
}

\author{
BD Madurapperuma ${ }^{\mathrm{a}}$, AAN Nishad ${ }^{\mathrm{b}}$, JS Borges ${ }^{\mathrm{c}}$, DIK Solangaarachchi ${ }^{\mathrm{d}}$, RV Kangath ${ }^{\mathrm{e}}$, SA Hewage
}

\begin{abstract}
Background: Sexually Transmitted Infections (STIs) are a major global public health issue leading to many physical, psychological and social consequences. Sri Lanka has a low prevalence of HIV and needs to target key population (KPs) at higher risk of infection. This study examines the district wise STI incidences and KPs in Sri Lanka to evaluate the trends and relationships of STIs and to provide recommendations for further investigations.
\end{abstract}

Methods: Data were extracted from the National STD/AIDS Control Programme (NSACP) report for the year 2015 in Sri Lanka. Canonical Correspondence Analysis (CCA) was carried out to identify how STIs correlate with male/female sex workers within districts using PC-ORD ${ }_{4}$ software.

Results: Colombo district was at high risk for all tested STIs. The relationship of STIs among districts was examined by CCA and three distinguishable clusters were identified. The first group included seven districts and four STIs. The second group included five districts associated with genital herpes. Third group comprised of two districts correlated with late syphilis and gonorrhoea. Most districts with high STI incidences correlated well with districts with densely clustered KPs. Districts where KPs are clustered should be prioritized for STI/HIV prevention programmes. Both STIs and KPs are mainly clustered around tourist destinations.

Conclusion: It is useful to monitor the alcohol and drug addictions for the patients and conducting STI prevention programs in vulnerable areas.

Key words: sexually transmitted infections (STIs), key populations, Sri Lanka, mapping, canonical correspondence analysis

Sri Lanka Journal of Obstetrics and Gynaecology 2018; 40: 31-38

DOI: http://doi.org/10.4038/sljog.v40i2.7844

\section{Introduction}

Sexually Transmitted Infections (STI), defined as bacterial, viral or parasitic infections predominantly spread by sexual contact, are one of the leading cause of mortality and morbidity around the world. Human immunodeficiency virus (HIV) infection leading to Acquired Immunodeficiency Syndrome (AIDS) has resulted in 1.1 million deaths around the world in 2015 alone, and the World Health Organization (WHO) declares HIV as a major global public health issue ${ }^{1}$. It

${ }^{a}$ Lecturer, Departments of Forestry and Wildland Resources and Environmental Science and Management, Humboldt State University, Arcata, CA 95521,USA.

${ }^{\mathrm{b}}$ Registrar in Medicine, Teaching Hospital, Batticola, Sri Lanka.

' Graduate, Department of Environmental Science and Management, Humboldt State University, Arcata, CA 95521, USA.

' System Engineer, Computer Centre, Faculty of Medicine, University of Kelaniya, Sri Lanka.

e Physician Infectious Diseases, Santa Rosa Veterans Clinic, CA 95403, USA.

${ }^{\mathrm{f}}$ Registrar in Community Medicine, National Cancer Control Programme, Ministry of Health, Sri Lanka.

Correspondence: BDM, e-mail: <bdm280@humboldt.edu>

(iD http://orcid.org/0000-0003-2786-4477

Competing interest: The authors report no conflict of interest 
is estimated that more than one million STIs other than HIV are acquired every day worldwide, and 36.7 million people in the world were living with STIs at the end of $2015^{2}$. The burden of STIs is not limited by geographic or socio-economic boundaries. 125 million people were living with one of main four curable STIs (gonorrhoea, chlamydia, syphilis or trichomoniasis) in the WHO regions of the Americas in 2008 and the same figure South East Asia region was 128 million². While both developed and developing countries fight against STIs, the burden of STIs is greater in lowincome countries ${ }^{2}$ leading to a vicious cycle between the disease burden and poverty.

Sri Lanka is a low prevalent country with an upward trend for HIV infection ${ }^{3}$. At the end of 2015, approximately 4000 adults aged above 15 years and less than 200 children below 15 years were estimated to be living with HIV infection in the country, which made the HIV prevalence less than $0.1 \%{ }^{3}$. A total of 9,129 new STIs were diagnosed among those who attended National STD/AIDS Control Programme during $2016^{4}$. Out of these new diagnoses, genital herpes was the leading diagnosis (33\%), followed by non-gonococcal infections (24\%) and genital warts (23\%). Syphilis contributed to $10 \%$ of new diagnosis, gonorrhoea to $3 \%$ and trichomoniasis to $1 \%$. However, the World Bank claims that only $10-15 \%$ of STI cases are reported by government clinics, and every year estimate for detected STI cases in Sri Lanka vary from 60,000 200,000 approximately5.

Consequences of STIs have a profound impact on sexual and reproductive health. Long term effects of STIs like subfertility are more profound than immediate adverse physical outcomes ${ }^{6}$. In addition to direct physical impact, psychological and social consequences of STIs have a major bearing on the quality of life of the patient and immediate relatives. The psychological and social consequences are multiplied by the stigma and discrimination attached with STIs ${ }^{7}$. Evidence shows that stigma related to STIs undermines testing for STIs, treatment and partner notification ${ }^{8}$. The low disease burden in Sri Lanka discussed above is most likely to represent only the tip of the iceberg due to the social stigma and discrimination associated with STIs. Repeated surveys conducted in Sri Lanka have indicated continuing high level of stigma towards people living with AIDS (PLWA) ${ }^{5}$. High level of social stigma towards STIs preventing access to services is only one of such risk factors which indicate the vulnerability of the Sri Lankan population for rapid spread of STIs. Other risk factors include low condom use, commercial sex, high inbound and outbound migration rates, rising trend in injecting drug users (IDUs) and low level of knowledge on HIV and STIs. being a low prevalence country at the moment, these factors in combination pose a major threat for rapid spread, leading to high prevalence of STIs in Sri Lanka, if necessary preventive actions are not taken.

Evidence suggests that in low prevalence settings, the focus of HIV and STI prevention programs should be targeted at key population (KP) groups to gain effective outcomes ${ }^{9}$. Furthermore, high coverage of such highrisk populations should be a priority in HIV/STI control programs ${ }^{10,11}$. Preventive strategies for any disease require accurate identification of the epidemiological profile. An understanding of HIV and STI prevalence and trends, as well as the prevalence and distribution of behaviours that contribute to the spread of the disease should be supplemented by national monitoring systems for effective prevention response ${ }^{12}$. The National STD/AIDS Control Programme (NSACP), the national focal point for STIs in Sri Lanka, has identified targeting KPs as a priority working area, and target female sex workers (FSW), men who have sex with men (MSM), people who inject drugs (PWID) and clients of sex workers as key population groups. With the empowered national commitment to "end AIDS as a public health threat" by 2025 , Sri Lanka needs to reduce the number of new HIV infections and AIDS related deaths by $90 \%$ compared to that in $2010^{13}$. Achieving this target definitely needs more focus on identified key populations in the country with regard to their epidemiological profile. This study assessed the extent of this important association between geographical clustering of STIs and high density of KPs, by determining district wise incidences of separate STIs and by clustering the STI risk areas and KPs using geographic mapping.

\section{Materials and methods}

Data on separate STIs and national size estimations of most at risk populations for HIV in Sri Lanka were collected from the annual report published by the NSACP which is the national focal point is responsible for control and prevention of STIs in the country ${ }^{14}$. The data was transformed to tabulate formats for mapping and multivariate analysis. The tabulated data consists of 2015 district wise STIs cases, sex, and sex workers' information and drug users. We calculated number of (FSWs) per 100,000 male population, number of FSWs per 100,000 female population, number of male sex workers (MSWs) per 100,000 males, people who used drugs (PWUD) drug users per 100,000 population and injecting drug users (IDU) 
per 100,000 population. Two data matrices of number of cases such as, disease incidence, and male/female sex workers and drug users were used for multivariate analysis using $\mathrm{PC}-\mathrm{ORD}_{4}$ software. Multivariate Analysis was carried out to find the trends and relationships of STIs within the geographic regions. The maps were then drawn using ArcMap $^{\odot}$ to identify the hotspots for STIs.

\section{Results}

District wise STI incidences were mapped for the identified 2015 cases to identify the risk areas (Figure 1). The incidences were calculated using the ratio of STI cases and district population in terms of 100,000 people. HIV prevalence is high in the Western Province and apart from that the other two districts that have reported high prevalence are Puttalum and Vavuniya. In general, HIV prevalence was notably high along the coastal zones from Puttalam to Galle spanning north-west to south. If the trend is considered there does not appear to be an increasing trend in Ampara (Figure 1). Many districts showed moderate risk for genital herpes with hotspots in Vavuniya and Ampara districts that these results are generated from the 2015 NSACP annual report. Genital warts showed a similar trend, but with a lower density. Distribution of nongonococcal infections, which is the second most common STI in Sri Lanka, closely resembles that of HIV. Early syphilis incidence rate was low throughout the country and Colombo, Galle and Kilinochchi reported the highest incidences. Late syphilis incidences were notably high in Polonnaruwa and Colombo. Moreover, late syphilis cases for both male and female were significantly higher $(\mathrm{P}<0.05)$ than early syphilis.

The relationship of STIs among districts and sex workers were examined using Canonical Correspondence Analysis (CCA). The axis 1 and axis 2 of the ordination diagram describe the linear combinations of the explanatory variables. Three distinguishable
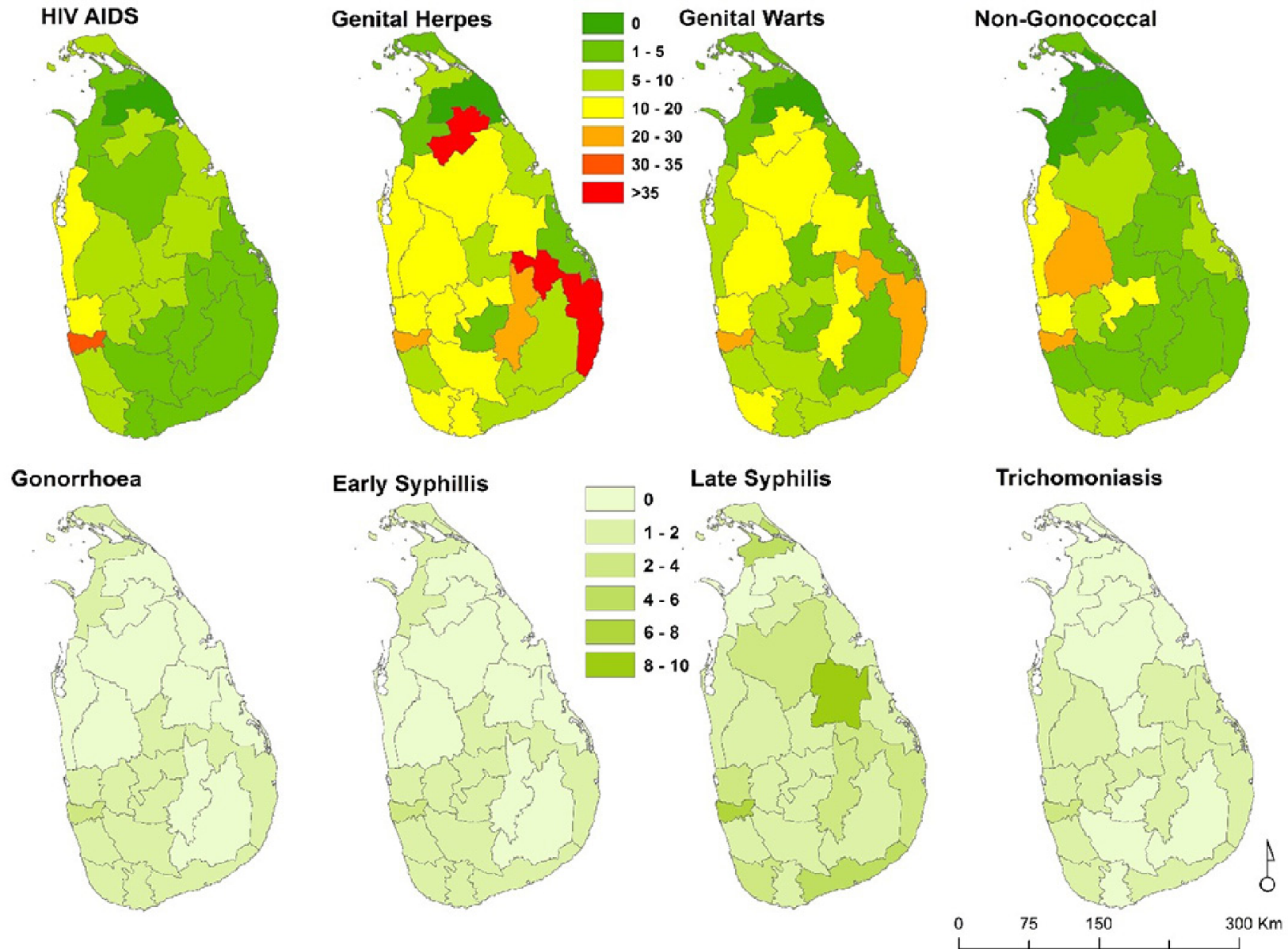

Figure 1. Maps showing district wise STIs incidences (per 1000,000 people) calculated using the ratios of total no. of cases and district population. 
clusters of districts were identified. The first group included seven districts and four STIs viz., HIV, early syphilis, genital warts and trichomoniasis. The second group included five districts viz., Matale, Ratnapura, Trincomalee, Moneragala, and Puttalam that associated with genital herpes. In this group, Ampara and Vavuniya districts were separated towards left side of Axis 1, while those districts were hotspots for the reported cases (Figure 1). The third group comprised of Kalutara and Hambantota districts correlated with late syphilis and gonorrhoea. The high positive correlations were observed for early syphilis (0.72) and HIV (0.63) in the Axis 1 of the CCA ordination, whereas high negative correlation were observed for late syphilis and gonorrhoea (-0.52 in each) in the Axis 2 of the CCA ordination (Figure 2). CCA ordination in relation to sex workers depicted that Colombo and Gampaha districts were highly correlated with male sex workers and direct/indirect drug users respectively (Figure 3). The results are comparable with the size estimation of KP groups (Figures 1 and 4). There was a high positive correlation of injecting drug users (0.66), drug users (0.64) and MSWs (0.31) in the Axis 1of the CCA.
The gender, Female Sex Workers on a peak day (Peak FSW), Men having Sex with Men (MSM), FSWs to 100,000 male ratios on peak day (Peak FSW M) and People Who Use Drugs (PWUD) were mapped to identify high-risk districts for sex workers, which are likely to be associated with STI (Figure 4). Female sex workers' incidences were considerably higher than male sex workers except in Jaffna, Mannar, and Kalutara districts. Drug users' prevalence was vibrant along the north-west coast and southern coastal districts.

Risk populations for STI were analyzed over time spanning from 2013 to 2015 (Figure 5). Of the STIs, almost all districts showed a high incidence for genital warts, genital herpes and late syphilis in 2015 than previous years. Overall, Colombo district showed a peak risk for almost all STI cases. An increasing trend of risks for some STIs namely, trichomoniasis, genital warts, genital herpes and gonorrhea were observed in Polonnaruwa with a distinct peak in 2015. Similarly, genital warts and genital herpes incidence increase twice than the previous years in Vavuniya.

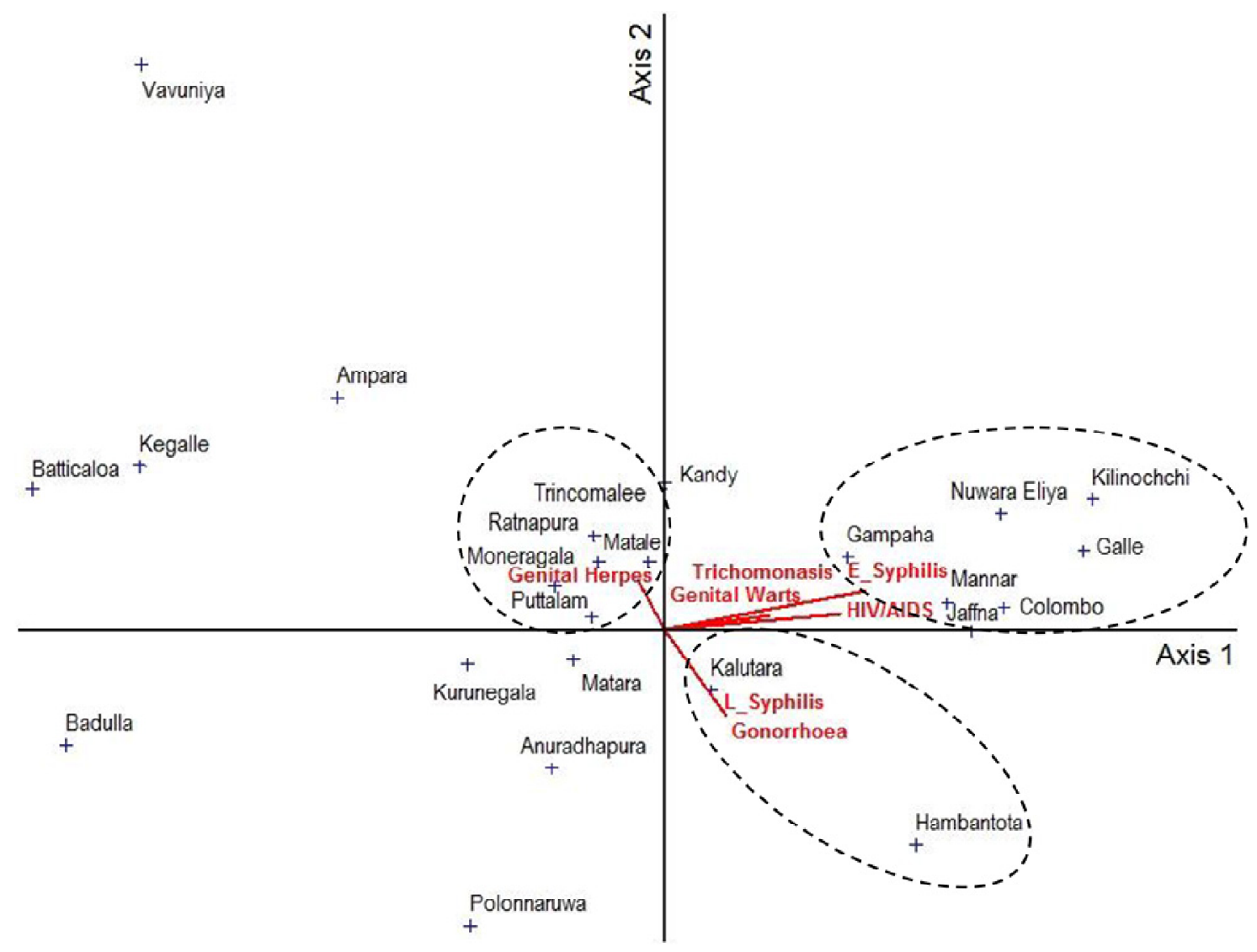

Figure 2. Canonical correspondence analysis ordination of species in terms of STIs incidences within districts. Joint plot was performed at 0.15 cut off levels. The joint plot factors were genital herpes, trichomoniasis, genital warts, early syphilis, non STIs, gonorrhoea, and late syphilis. 


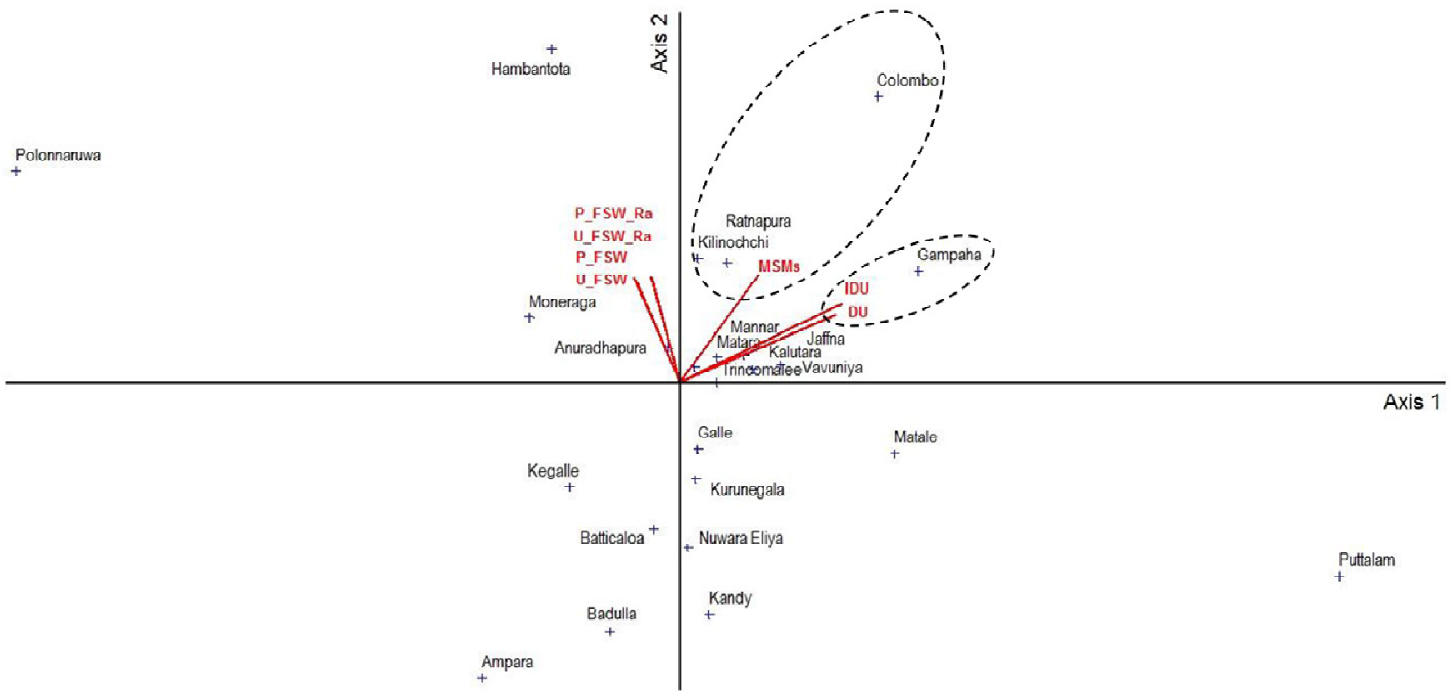

Figure 3. Canonical correspondence analysis ordination of species in terms of sex workers and drug users within districts. Joint plot was performed at 0.15 cut off levels, where the minimal value for all the second variables displayed in an ordination diagram. The joint plot factors were injecting drug users (IDU), drug users (DU), men having sex with men (MSM), Female Sex Workers on usual day (U_FSWs), Female Sex Workers on Peak day (P_FSW), FSWs to 100,000 male ratio on usual day (U_FSW_Ra), and FSWs to 100,000 male ratio on peak day (P_FSW_Ra).
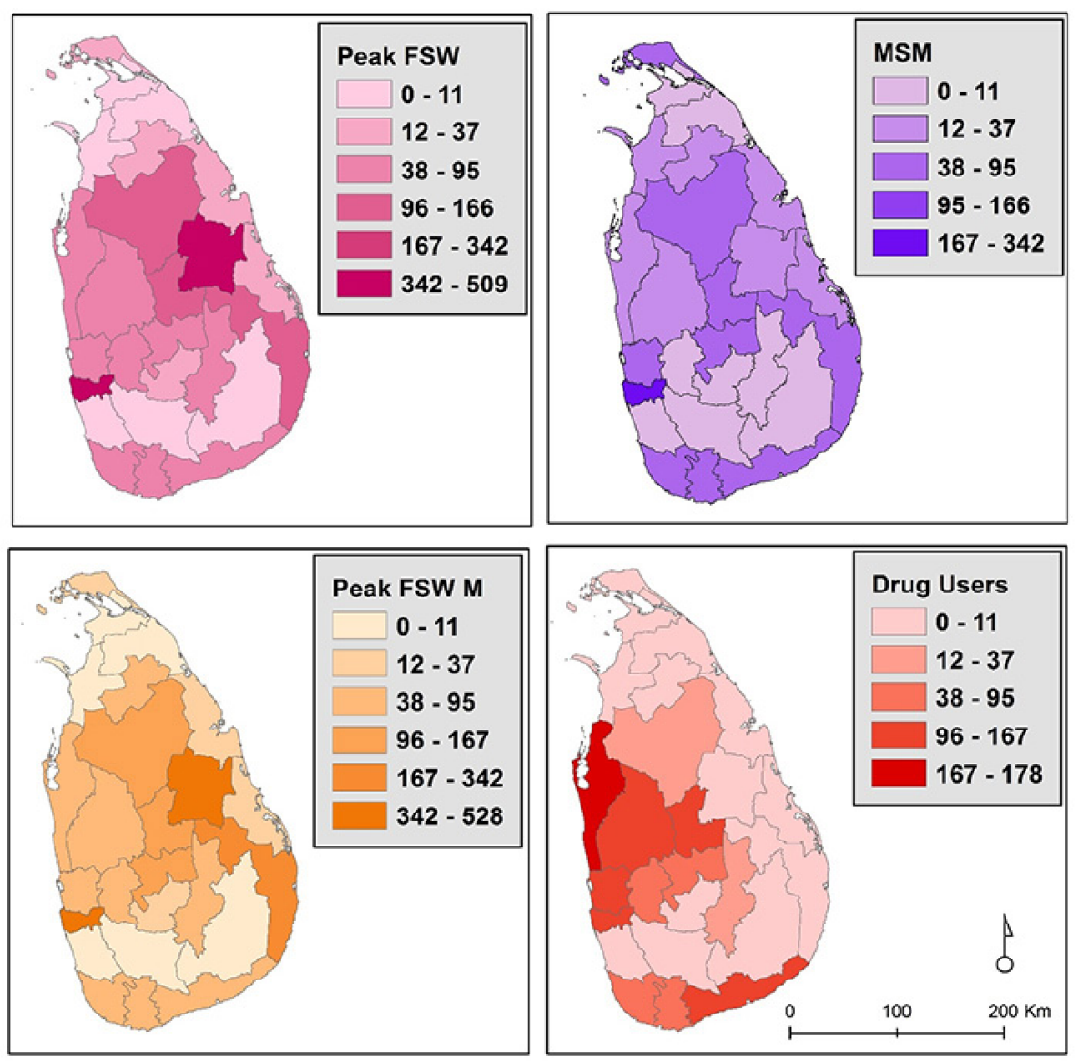

Figure 4. Maps showing district wise sex worker incidences (per 100,000 people) calculated using the ratios of total no. of sex workers and district population. 

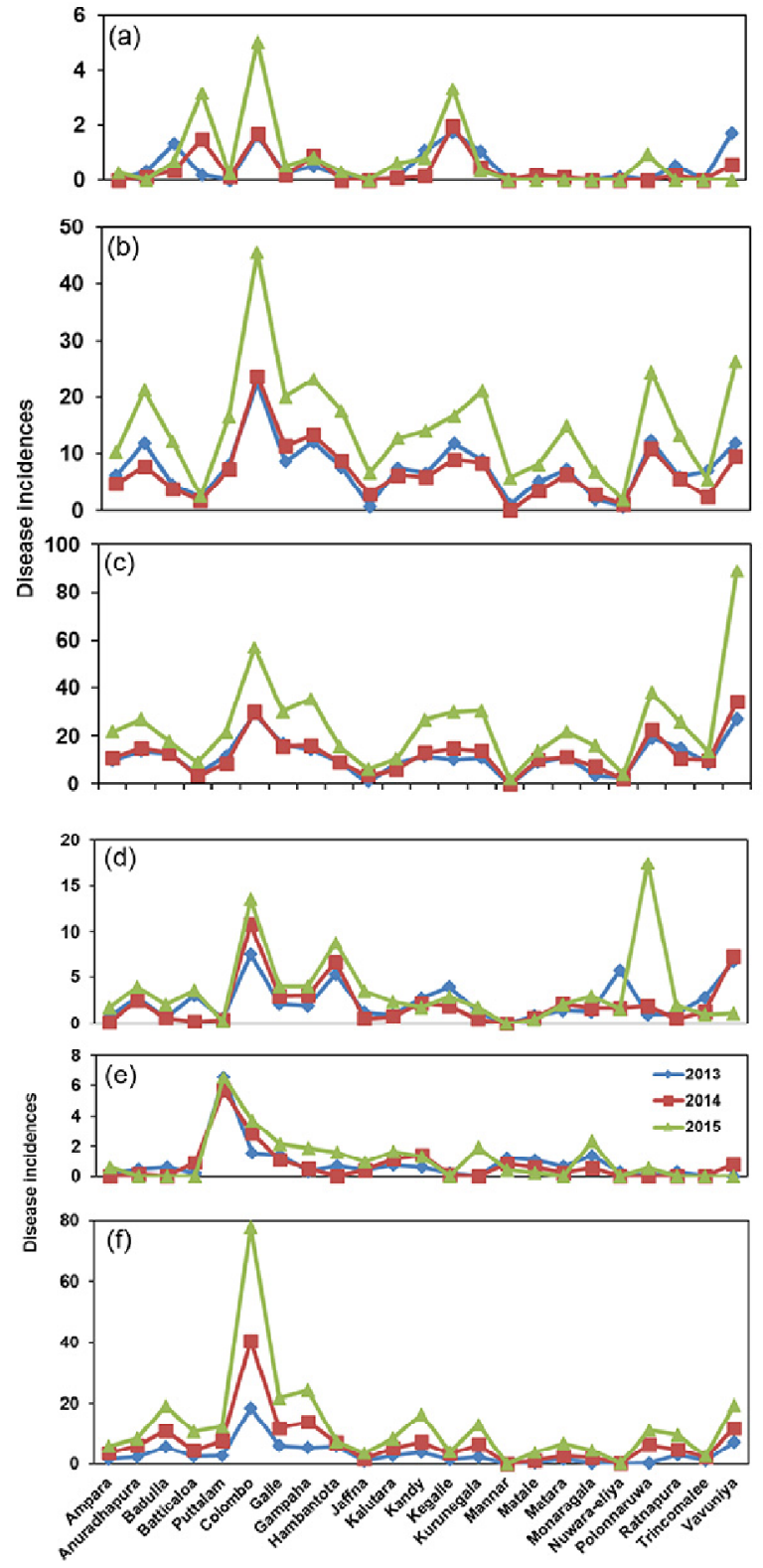

Figure 5. Time series analysis of STI diseases: (a) trichomoniasis (b) genital warts (c) genital herpes (d) gonorrhea (e) early syphilis (f) late syphilis among districts of Sri Lanka.

\section{Discussion}

This study used data collected by the National STD/ AIDS Control Programme which are timely and collected through its well-established network of clinics around the country. However, clinically collected data that we used for these ecological studies have biases. For example, STI data do not adequately describe the factors associated with transmission of these infections in local communities and it is challenging to collect human sexual behaviour from traditional surveys ${ }^{15}$.
The maps were useful to identify STI hotspots in Sri Lanka and to understand how the distribution of KPs like sex workers and drug users are associated with incidence of STI. In addition, we utilized CCA to explain the relationship between two multivariate data sets all measured in same individual/subject.

Despite the low prevalence of HIV in Sri Lanka, we could identify several districts with higher incidence rates (Figure 1) for different STIs. This also makes these districts at risk for rapid spread of HIV if necessary preventive measures were not taken. Colombo district recorded high prevalence for almost all STIs. This could be due to many reasons. Larger proportions of inbound migrants in the district of Colombo, availability of sex workers due to night club and massage parlour ${ }^{16}$ than in other districts and tourist attraction to the capital city, are only few of these. Since most of these factors are not amenable to primordial preventive measures, most effective would be to target primary and secondary preventive measures, such as educating and periodical screening of the KPs.

The coastal areas from north-west to south are such identified at risk geographical areas. These areas been famous tourist destinations leading to high density of tourist hotels and higher availability of sex workers could be the underlying reason for this distribution. Syphilis infection is called an 'early' case if a patient has been infected for a year or less such as during its primary or secondary stages ${ }^{17}$. People who have early syphilis can more easily spread the infection to their sex partners mostly among MSM; but women and newborn born to infected mothers are also at risk of infection ${ }^{17}$. Therefore, our findings on identifying risk areas for early syphilis are useful to monitor disease prevalence of women and newborn children.

Research around the globe suggest that exposure to travellers results in an increase of STI in developing countries $^{18,19}$, and tourism is associated with higher incidence of STIs ${ }^{18}$. This knowledge can be used to partly explain the trends and patterns of STI cases we identified by our analysis, which shows higher density of patients around the coastal belt from Puttalam to Hambantota and in towns with ancient sacred places like Anuradhapura and Polonnaruwa. These findings warrants taking up innovative preventive measures to avert scaling up of the disease in these at-risk areas. Making STI screening mandatory for tourists on applying visa is such novel measure, but this national level policy decision will need to be weighed for its benefit against the possible financial loss and other adverse outcomes to the country. 
Aggregation of sex workers in Northern (Vavuniya), North-Central (Anuradhapura and Polonnaruwa) and Eastern (Ampara) provinces could reflect the relationship with the higher density or armed forces located in these areas. But this association needs to be further studied and specific preventive measures to address route causes need to be recommended depending on conclusions based on results. Until such study findings are available, our study findings can be used as evidence to scale up general STI preventive services like public awareness programmes in these areas.

In comparison of maps on STI incidence cases against KPs, a larger proportion of area with high density of STI incidence cases overlapped with areas highly populated with FSW and/or PWUD. This result was predicted and justifies accelerating STI/HIV preventive programmes in areas with high density of KPs. On the other hand, districts in the Southern province which show high density with KPs did not show higher incidences of STI incidence cases. This was unexpected, and has not been reported in literature before. Therefore, further research is warranted to study the inverse association in depth. Moreover, the policy makers and national level decision makers need to be aware of this finding, which reflect a future threat for STI epidemics.

Overall, it is possible that the low prevalence of STIs are due to a variety of reasons previously discussed in addition to the stigma associated with attending clinics, seeking treatment from private health professionals and the general unreliability of in clinical diagnosing an STI $^{20}$.

\section{Limitations}

STI incidence cases were obtained from the National STD/AIDS programme, and it is likely these data are underestimations of the true counts. However, correction of cases is done for HIV. A study in 1982 reported $40 \%$ of patients with STI taking treatments from private sector ${ }^{21}$, and this gap only has increased over time $^{5}$. However, this was the best available source of information with an island wide coverage to be used in the study. Continuous monitoring and evaluation of STI is useful to address the issues of the National STD/ AIDS programme, such as available facilities including experts, trained MLTs and investigation facilities. To control the STI, it is essential to provide more MLTs to the STI affected areas and also make campaign activities for mobilising the risk groups to attend the clinics.

\section{Conclusion and recommendations}

Geographical mapping confirmed that higher numbers of incidences of STIs are clustered in areas where KPs can be found densely. Therefore, prioritizing these districts for STI/HIV preventive programmes and scaling up of available programmes in these districts are recommended before focusing on non-endemic areas. It is also important to consider why certain regions i.e. Mullaitivu reporting of low STI incidences. STIs and KPs are mainly clustered around tourist attractions like the coastal strip and ancient sacred places, indicating the strong relationship of spread of STIs with tourism. Further studies are recommended on exploring the underlying factors for districts in Southern province to have an inverse association between STIs and KPs, which will be extremely useful in tailoring STI/HIV preventive measures to suit the local context.

\section{References}

1. World Health Organization. HIV/AIDS Fact sheet. 2016. Accessible through http://www.who.int/ mediacentre/factsheets/fs360/en/

2. World Health Organization. Report on Sexually Transmitted Infections (STIs). 2016. Accessible through www.apps.who.int $>$ WHO_RHR 12.31_eng.pdf

3. National STD/AIDS Control Programme Sri Lanka. Annual Report 2016. Situation of HIV epidemic in Sri Lanka. Pg 3-15. Ministry of Health; Sri Lanka. 2017.

4. National STD/AIDS Control Programme Sri Lanka. Annual Report 2016. Situation of STIs during 2016. Pg 35-48. Ministry of Health; Sri Lanka. 2017.

5. The World Bank. HIV/AIDS in Sri Lanka. 2012. Accessible through http://www.worldbank.org/en/ news/feature/2012/07/10/hiv-aids-sri-lanka

6. Aral SO. Sexually transmitted diseases: magnitude, determinants and consequences. Int J STD AIDS 2001; 12(4): 211-5.

7. Fatoki B. Understanding the causes and effects of stigma and discrimination in the lives of HIV people living with HIV/AIDS: qualitative study. J AIDS Clin Res 2016; 7(12).

8. Morris JL, Lippman SA, Philip S, Bernstein K, Neilands TB. Lightfoot M. Sexually Transmitted Infection related to stigma and shame among African American male youth: Implications for 
testing practices, partner notification and treatment. AIDS Patient Care STDS 2014; 28(9): 499-506.

9. Dallabetta G, Wi TEC, Nielsen G. Prevention and control of STD and HIV infection in developing countries. In: Holmes KK, Sparling P, Stamm W, Piot P, Wasserheit J, Corey L, et al., eds. Sexually transmitted diseases. 4th edn. New York, NY: McGraw-Hill; 2008.

10. Steen R, Mogasale V, Wi T, Singh AK, Das A, Daly C, George, B, Neilsen, G, Loo, V, Dallabetta, G. Pursuing scale and quality in STI interventions with sex workers: initial results from Avahan India AIDS Initiative. Sex Transm Infect 2006; 82: 381-5. doi: 10.1136/sti.2006.020438 pmid: 17012513

11. Pisani E, Girault P, Gultom M, Sukartini N, Kumalawati J, Jazan S, Donegan, E. HIV, syphilis infection, and sexual practices among transgenders, male sex workers and other men who have sex with men in Jakarta, Indonesia. Sex Transm Infect 2004; 80: 536-40. doi: 10.1136/sti.2003.007500 pmid: 15572631 .

12. Bertozzi S, Padian NS, Wegbreit J, et al. Ch 18; HIV/AIDS Prevention and Treatment. In: Jamison DT, Breman JG, Measham AR et al., eds. Disease Control Priorities in Developing Countries. 2nd edn. New York: Oxford University Press; 2006.

13. National STD/AIDS Control Programme Sri Lanka. Annual Report 2016. Situation of STIs during 2016. Pg 22. Ministry of Health; Sri Lanka. 2017.
14. National STD/AIDS Control Programme. Annual report 2016. Ministry of Health; Sri Lanka.

15. Jayawardena KA, Silva KT, Jayawardena CK, Samarakoon S. Behavioural risk factors of men associated with transmission of sexually transmitted infections (STIs) in Sri Lanka. WHO-SE Asia J Public Hlth 2012; 1(1): 69-75.

16. Gnanadass, W. UNF's move to set up Lanka's red light district. The Sunday Leader, 29th June 2003; 9(50). http://www.thesundayleader.lk/archive/ 20030629/spotlight-more.htm

17. Centre for Disease Control. Syphilis Fact Sheet. Available at: https://www.cdc.gov/std/syphilis/ stdfact-syphilis.htm

18. Vivancos R, Abubakar I, Hunter, PR. Foreign travel, casual sex, and sexually transmitted infections: systematic review and meta-analysis. Int $\mathrm{J}$ Infect Dis 2010; 14: 842-51.

19. Matteelli A, Carosi G. Sexually transmitted diseases in travelers. Travel Med 2001; 32: 1063-1067.

20. Samarawickrema NA, Tabrizi SN, Young E, Gunawardena PA, Garland, SM. Prevalence of Trichomonas vaginalis, Chlamydia trachomatis, Neisseria gonorrhoeae and human papilloma virus in a sexual health clinic setting in urban Sri Lanka. Int J STD AIDS 2015; 26(10), 733 - 739. DOI: $10.1177 / 0956462414552813$

21. Catterall, RD. Sexually transmitted diseases in India and Sri Lanka. Brit J Vener Dis 1982; 58(5): 338-339. 